\title{
Physiotherapists perceptions on informed consent and role in the healthcare system, in Europe
}

3

4 Nadinne Roman ${ }^{1 \uparrow, ~ S i l v i u ~ C a l o i a n ~}{ }^{1 \uparrow}$, Angela Repanovici², Roxana Miclaus ${ }^{1}$, Gabriela Sechel ${ }^{1}$, $5 \quad$ Liliana Rogozea ${ }^{1}$

71 Department of Fundamental, Prophilactial and Clinical Disciplines, Faculty of Medicine, 8 Transilvania University of Brasov, Brasov, Romania

92 Department of Product Design, Mechatronics and Environment, Faculty of Product Design and 10 Environment. Transilvania University of Brasov, Brasov Romania

11

12 Corresponding author

13 e-mail: roxileta2009@yahoo.com (RM)

14

15 NR and SC are Joint Senior Authors

16 


\section{Abstract:}

Introduction

Physiotherapy has developed over the last century, and the physiotherapists' professional identity is growing. The heterogeneity of physiotherapy studies in Europe, local government, and health policies have influenced the responsibilities and ethical reasoning of physiotherapists. Our study aims to explore the perceptions and differences regarding informed consent (IC) and the role of physiotherapists in healthcare in an educational, legislative, and health policy context.

Material and Methods

A cross-sectional survey was distributed online to physiotherapist graduates in Europe. The survey contained two open questions regarding IC and assumed role in healthcare. The data was operated to and analyzed by using a theory-based approach (open and axial coding), providing a qualitative spectrum of categories for the two items linked on IC and the role in healthcare.

\section{Results}

Eight categories of issues related to IC and seven categories related to the role in healthcare were identified. The physiotherapist graduates from Romania, France, Belgium, Italy, and other countries from inside and outside European Union response rate was $81.85 \%(\mathrm{n}=248$ from 303$)$ for the item related to IC and $71.62 \%(n=217)$ to the second item related to the role in healthcare. A percent of $24.20 \%(n=60)$ are still considering IC a simple patient information process, while $23.40 \%$ (58) have linked IC with ethically and legally issues, $21.67 \%(\mathrm{n}=51)$ of physiotherapists are minimizing their role in healthcare at restoring physical independence, while $6.91 \%(\mathrm{n}=27)$ are aware of their multidisciplinary role. The country comparison analysis revealed that physiotherapists from UK and Italy are more aware regarding IC and that physiotherapists from Belgium and France are better oriented regarding their role in healthcare.

Conclusions 
41 The study shows that heterogeneity, legislation, and healthcare system differences influence

42 physiotherapists professional development. Future research is needed to establish the reason for the

43 reduced perception of physiotherapists regarding their role as health promoters.

44 Keywords: physiotherapy; ethical issues, informed consent, healthcare

45 Introduction

46 Throughout the evolution of the physiotherapist profession, the concept of professional identity has

47 developed, assuming the existence/presence of a set of moral norms, abilities, and skills designed to

48 define the profession of the physiotherapist towards high standards (1)(2)(3). The occupation of the

49 physiotherapist has developed throughout Europe during the last century as a profession assimilated to

50 healthcare professionals (4)(5)(6). In most countries in Europe and around the world, the profession of

51 physiotherapy has been regulated and recognized so far, leading to the occurrence of ethical norms that

52 must be respected and compliance with high standards of practice (7)(8)(9). Romania is the only country

53 of the European Union where the physiotherapist profession was partially regulated in 2016, and the

54 professional organization has incomplete legislation (10).

55 The professional identity of those performing social work, as in the case of physiotherapists, is a

56 continuous process that is determined by the context, factors, or situations that may occur at work. It is

57 linked to specific roles that are attributed more from a legal point of view than relative to the complexity

58 and potential conceptualization of each profession. Formation of the professional identity of

59 physiotherapists takes place over time. The workplace, the staff involved in everyday activities, the moral

60 principles and values of each, the accumulated experience, and the moral conflicts arising from the

61 intersection of individual values and beliefs are elements which influence the accumulation of

62 professional skills (11)(12).

63 The legislation, health systems, and study programs in physiotherapy vary from one country to another,

64 although competencies are mostly similar, with few exceptions. However, the differences between 
countries health systems are essential, especially in the context of migratory physiotherapists, especially in European territory. According to the European database on regulated professions, from 1997 to 2013, 19973 physiotherapists migrated to European countries. Ethical issues related to the profession of physiotherapy also arise due to different systems and health legislation in the context of migration (13) $(14)(15)$.

In addition to the physical and functional rehabilitation skills and abilities, physiotherapists play a vital role in the prophylaxis, health, promotion of physical activity and long-term outcomes after different surgical procedures, being part of the medical profession with a significant impact on the quality of life $(16,17)$.

The ethical issues encountered in medical practice, legislative norms, research, and medical technology, marks this multidisciplinary profession, which influences medical practice and population. In the context of the heterogeneity of studies, legislation, health systems, and the needs of the high population, physiotherapists must provide high-quality health services and be involved in promoting health. Considering the increased number of elderly and disabled people, as well as the risk of cardiovascular disease and premature death due to physical inactivity worldwide, physiotherapists have to respect high professional standards (18)(19)(20).

So far, research shows that the professionalism and attitude of the physiotherapist have considerable repercussions on the evolution of the rehabilitation process (21)(22). As a medical act in which the physiotherapist often guides the patient in the physical therapy program, the approach of physiotherapists is often paternalist and often does not involve the patient in creating the content of the physiotherapy program, omitting cultural or social elements of patients, and often granting importance only to physical rehabilitation and less motivation through socio-cultural aspects (23)(24).

Additionally to the ethical issues encountered in medical practice, the current legislative norms, as well as the evolution of medical research and technology, make their mark on this multidisciplinary profession, resulting in multiple professional responsibilities affecting the quality of healthcare services. Considering 
the specificity of physiotherapy care, which involves many issues, create difficult circumstances for both

91 patients and physiotherapists and medical staff. Physically and emotionally prolonged contact of the

92 patient with the physiotherapist, the lack of a specific framework for obtaining IC, but also the legislative,

93 educational and professional differences specific to each country influence the physiotherapy practice.

94 The ethical issues encountered in the physiotherapist's medical practice are also difficulties of practice.

$95 \quad(25)(26)(27)(28)(29)$.

96

97
Regarding both patients' and physiotherapists' perspectives about the rehabilitation process, the most important ability appreciated by patients is communication, followed by the therapist's focus on the patient himself and not just on the present disorder. These aspects confirm the need to develop a professional relationship between the patient and the therapist, precisely because of the primary purpose of rehabilitation, namely the patient's autonomy. Within the relationship developed with the patient, the therapist should draw some guidelines and recognize critical ethical issues, but also extract ethical principles and connect them to particular clinical contexts (31). It is crucial for the physical therapist to assume the level of practical authority, to have the ability to connect ideas, to understand the relationships and to have the knowledge necessary to make the right decision finally.

Regarding the process of obtaining informed consent (IC), one of the particularities of applying the therapies in physiotherapy, but also from the perspective of obtaining informed consent, is related to the specificity and dynamics of the physical therapy sessions. In most cases, techniques and methods used throughout treatment change, often even during a physiotherapy session, so the physiotherapist has to make multiple decisions during a treatment session. There are no strict protocols, and such protocols cannot be applied, and if they exist, physiotherapy is a medical branch that treats the patient $90 \%$ and less the illness itself. The previous studies regarding IC show that most physiotherapists obtain patient consent at the onset of treatment, along with the patient evaluation, not repeating this process in every change of techniques or maneuvers used (32)(24)(28). 
114 Given the many factors that may influence the physiotherapists' professionalism, the main objective of

115 our research was to explore physiotherapists' perceptions of informed consent (IC) and the level of

116 development of professional identity in the context of educational, legislative and professional

117 differences.

\section{Material and methods}

121 To investigate the perception of physiotherapists in the medical practice, we have sought to contextualize

122 the concepts and ethical principles resulting from the literature revision. A descriptive, qualitative and

123 comparative study was carried out through a questionnaire survey. The operationalization of the ethical

124 elements extracted through the review of the literature was carried out to link the ethical concepts and

125 premises of reality, to be able to objectively measure the perception of physiotherapists on ethical aspects

126 of professional practice. Through the process of operationalization, we identified several dimensions of

127 ethical issues in the physiotherapy care process, which we later transposed into a questionnaire addressed

128 to physiotherapists.

129 We have distributed a questionnaire addressed to graduate physiotherapists among several European

130 Union countries. The questionnaire used was qualitative research in a small percentage, with two open

131 questions about physiotherapists' perception of IC and their role in healthcare.

132 The survey was distributed online through the Survey Monkey platform. Before applying the survey, we

133 have obtained the approval of The Ethics Commission of the Faculty of Medicine of the Transilvania

134 University of Brașov. We have disseminated the questionnaire online, by contacting different professional

135 physiotherapy associations within the European Union, and as well through the social media pages of 136 professional groups. The questionnaires were distributed from November 2017 until July 2018, initially in 
Romanian, and after were translated into English, French, and Italian, by translators of specific languages and then distributed once again. The sampling was random.

The sample size was 303 respondents. The questionnaire was distributed to physiotherapists in an online environment using physiotherapy groups from the social networks in Romania, Belgium, France, the

141 United Kingdom, Spain, Portugal, Switzerland, Hungary, Italy and other groups without specific 142 geographical allocations. We have contacted all physiotherapy associations in Europe, but most of the 143 answers were negative or the response was lacking. The informed consent was obtained implicitly by 144 filling in the questionnaire. No personal data has been collected under European law. Initially, 331 questionnaires were collected, of which 28 were removed due to missing or incomplete data. In the case of the two open-ended questions, the answer rate was $81.85 \%(n=248)$ to the first open question related to $\mathrm{CI}$ and $71.62 \%(\mathrm{n}=217)$ to the second item related to the role in healthcare.

Data operationalization

\section{Informed Consent}

The responses gathered from the two open items varied and it was necessary to distinguish between the types of response. Depending on the description, several categories have been differentiated by operating and encoding data. Inductive coding was applied separately by two of the team members, following a few steps: 1) Reading raw data and creating codes to cover the sample based on responses; 2) re-evaluating

154 the sample and applying the codes for each respondent and creating another code for irrelevant answers 155 that did not correspond to the question. We have added a code for respondents which claimed the lack of 156 IC at the onset of physiotherapy. A third member of the team has resolved misunderstandings.

157 After the coding, the responses were separated into seven categories, making an ordinal grading, 158 accounting as maximum complexity of responses related to patient rights and legal considerations, and at 159 the last level classifying the respondents who stated that they do not demand IC at the onset of treatment. 
160 The coding of responses was done both to obtain data that can be measured and analyzed and to be ranked

161 according to the efficiency or the correctness of the response, allowing us to order them on an ordinary

162 scale:

$1630=$ assigned to respondents who do not request IC,

1641 = assigned to irrelevant answers,

1652 = assigned to respondents who believe that obtaining IC is done to protect themselves against

166 malpractice

$1673=$ assigned to respondents who declared it to be an information process about the therapeutic program

$1684=$ assigned to respondents who thought IC is necessary to increase patient confidence

$1695=$ assigned to respondents who sought IC as a tool to determine good collaboration with the patient and

170 to integrate it into the physical therapy process

1716 = assigned to respondents who have declared patient consent or disagreement with the treatment

$1727=$ the most comprehensive and correct answers from legal, ethical, and professional perspectives.

\section{Assumed role in healthcare}

174 The second open question item of the questionnaire aimed to investigate the perception of 175 physiotherapists role in healthcare, as medical care providers. Data interpretation included a pre-review of 176 all responses and their categorization. Inductive coding was applied separately by two of the team 177 members, following a few steps: 1) Reading raw data and creating codes to cover the sample based on 178 responses; 2) re-evaluating the sample and applying the codes for each respondent and creating another 179 code for irrelevant answers that do not correspond to the question. A code added for those who said they 180 did not ask for IC at the onset of physiotherapy. A third member of the team has resolved 181 misunderstandings. This item of the questionnaire had a response rate of $71.62 \%$ (217 out of 303$)$. 
182 Response categories were differentiated into eight sections. The most complex and appropriate category

183 was considered the last one. The responses related to the prophylactic, therapeutic, and rehabilitation role,

184 which is, in fact, the definition of physiotherapy (16) and embraces the complex characteristics of the

185 physiotherapist profession.

186 0- Irrelevant answer

187 1- Role in rehabilitation

188 2-Restore physical / independent condition

189 3-Planning, evaluation, and application of physiotherapy

190 4-Improving the quality of life/condition

191 5-Interdisciplinary / binder in the medical team

1926 Essential / Complex

193 7-Prophylactic, curative and therapeutic

\section{Results}

\section{Demographic Analysis}

196 Statistical analysis was performed using SPSS 20. Descriptive analysis of the two items was

197 accomplished, and for comparative analysis, the non-parametric Kruskal-Wallis test was used to

198 determine the differences perceived related to IC and role in healthcare according to age, experience, type

199 of practice and countries of origin. Subsequently, pairwise comparisons were performed using Dunn's

200 (1964) procedure with a Bonferroni correction for multiple comparisons. Adjusted p-values are presented.

Table 1: Age and experience distribution

\begin{tabular}{cccccc} 
Age & $\begin{array}{c}\text { Item 1 } \\
\text { number/percent }\end{array}$ & $\begin{array}{c}\text { Item 2 } \\
\text { number/percent }\end{array}$ & Experience & $\begin{array}{c}\text { Item 1 } \\
\text { number/percent }\end{array}$ & $\begin{array}{c}\text { Item 2 } \\
\text { number/percent }\end{array}$ \\
\hline 21-30 Years & $105 / 42.33 \%$ & $94 / 43.31 \%$ & $1-3$ Years & $77 / 31.05 \%$ & $65 / 29.96$ \\
$31-40$ Years & $100 / 40.32 \%$ & $85 / 39.17 \%$ & $3-5$ Years & $29 / 11.69 \%$ & $31 / 14.29$
\end{tabular}




\begin{tabular}{lccccc} 
41-50 Years & $33 / 13.30 \%$ & $27 / 12.44 \%$ & $5-10$ Years & $60 / 24.20 \%$ & $51 / 23.50$ \\
$51-60$ Years & $7 / 2.82 \%$ & $8 / 3.68 \%$ & $10-20$ Years & $53 / 21.37 \%$ & $46 / 21.19$ \\
$>60$ Years & $3 / 1.20 \%$ & $3 / 1.38 \%$ & $>20$ Years & $29 / 11.69 \%$ & $24 / 11.06$ \\
Total & $248 / 100.00 \%$ & $217 /$ & Total & $248 / 100 \%$ & $217 / 100.00 \%$ \\
\hline
\end{tabular}

204 Within the first item, out of 248 respondents, $145(58.47 \%)$ respondents came from the private sector, 94

205 (37.91\%) from the public sector and 9 (3.62\%) from other mixed sectors. In the second item, out of 217 respondents, 125 (57.61\%) came from the private sector, $85(39.18 \%)$ and $7(3.21 \%)$ in the mixed sectors. 
Table 2 Crosstabulation of reason for IC demanding at physiotherapy onset by countries

209 respondents

\begin{tabular}{|c|c|c|c|c|c|c|c|c|c|}
\hline \multicolumn{10}{|c|}{ Reason for IC demanding * Countries Crosstabulation } \\
\hline \multirow[t]{2}{*}{ Count } & \multicolumn{7}{|c|}{ Country distribution } & \multicolumn{2}{|c|}{ Total } \\
\hline & Romania & Italy & France & Belgium & UK & $\mathrm{UE}$ & $\begin{array}{l}\text { Non- } \\
\text { UE }\end{array}$ & $\mathrm{N}$ & Percent \\
\hline Do not demand & 5 & 1 & 0 & 0 & 0 & 0 & 0 & 6 & $2.41 \%$ \\
\hline Irrelevant answers & 10 & 1 & 0 & 2 & 0 & 0 & 2 & 15 & $6.04 \%$ \\
\hline $\begin{array}{l}\text { Physiotherapist protection/ } \\
\text { malpractice }\end{array}$ & 6 & 3 & 6 & 2 & 0 & 0 & 6 & 23 & $9.27 \%$ \\
\hline Patient information & 40 & 3 & 5 & 4 & 3 & 2 & 3 & 60 & $24.20 \%$ \\
\hline To gain patient's trust & 7 & 0 & 0 & 0 & 0 & 0 & 2 & 9 & $3.63 \%$ \\
\hline Collaboration with patient & 14 & 3 & 6 & 5 & 0 & 0 & 1 & 29 & $11.70 \%$ \\
\hline For patient Consent & 18 & 6 & 4 & 3 & 5 & 3 & 9 & 48 & $19.35 \%$ \\
\hline Ethical and legal issues & 11 & 19 & 1 & 4 & 13 & 2 & 8 & 58 & $23.40 \%$ \\
\hline Total & 111 & 36 & 22 & 20 & 21 & 7 & 31 & 248 & $100.00 \%$ \\
\hline Percent & $44.75 \%$ & $14.52 \%$ & $8.89 \%$ & $8.07 \%$ & $8.46 \%$ & $2.82 \%$ & $12.50 \%$ & 248 & $100.00 \%$ \\
\hline Mean & 4.01 & 6.04 & 4.11 & 4.24 & 6.15 & 5.17 & 4.75 & & \\
\hline $\mathrm{Sd}$ & 1.942 & 1.870 & 1.711 & 1.895 & 1.424 & 1.722 & 2.111 & & \\
\hline 95\% CI Lower Bound & 3.61 & 5.23 & 3.26 & 3.21 & 5.48 & 3.36 & 3.86 & & \\
\hline 95\% CI Upper Bound & 4.41 & 6.85 & 4.96 & 5.26 & 6.82 & 6.97 & 5.64 & & \\
\hline Minimum & 0 & 0 & 2 & 1 & 3 & 3 & 1 & & \\
\hline Maximum & 7 & 7 & 7 & 7 & 7 & 7 & 7 & & \\
\hline
\end{tabular}


211 Table 3 Cross-tabulation of physiotherapists role in healthcare by countries respondents

\section{Assumed role in healthcare * Countries Crosstabulation}

\begin{tabular}{|c|c|c|c|c|c|c|c|c|c|}
\hline \multicolumn{10}{|l|}{ Count } \\
\hline & \multicolumn{7}{|c|}{ Country distribution } & \multirow[t]{3}{*}{ Total } & \multirow[t]{3}{*}{ Percent } \\
\hline & Romania & Italia & France & Belgium & UK & $\mathrm{UE}$ & Non- & & \\
\hline & & & & & & & UE & & \\
\hline Other & 12 & 1 & 0 & 0 & 0 & 1 & 1 & 15 & $23.50 \%$ \\
\hline Role in rehabilitation & 24 & 8 & 4 & 3 & 7 & 2 & 3 & 51 & $21.67 \%$ \\
\hline $\begin{array}{l}\text { Restore Physical Function/ } \\
\text { Independence }\end{array}$ & 21 & 6 & 2 & 5 & 6 & 1 & 6 & 47 & $11.06 \%$ \\
\hline $\begin{array}{l}\text { Planning, assessment and } \\
\text { application of physiotherapy }\end{array}$ & 13 & 0 & 2 & 0 & 3 & 0 & 6 & 24 & $10.60 \%$ \\
\hline $\begin{array}{l}\text { Improving the quality of life / } \\
\text { condition }\end{array}$ & 11 & 0 & 4 & 1 & 2 & 2 & 3 & 23 & $4.61 \%$ \\
\hline Interdisciplinary & 7 & 1 & 1 & 0 & 0 & 0 & 1 & 10 & $9.21 \%$ \\
\hline Essential / Complex & 9 & 4 & 3 & 2 & 1 & 0 & 1 & 20 & $12.44 \%$ \\
\hline $\begin{array}{l}\text { Promotion, prevention, } \\
\text { treatment/intervention, } \\
\text { habilitation and rehabilitation. }\end{array}$ & 5 & 7 & 3 & 8 & 1 & 0 & 3 & 27 & $6.91 \%$ \\
\hline Total & 102 & 27 & 19 & 19 & 20 & 6 & 24 & 217 & $100.0 \%$ \\
\hline Percent & $47.00 \%$ & $12.44 \%$ & $8.75 \%$ & $8.75 \%$ & $9.21 \%$ & $2.75 \%$ & $11.05 \%$ & 217 & $100 \%$ \\
\hline Mean & 2.60 & 3.74 & 3.89 & 4.18 & 2.45 & 2.00 & 3.21 & & \\
\hline $\mathrm{Sd}$ & 1.951 & 2.734 & 2.246 & 2.604 & 1.701 & 1.673 & 1.978 & & \\
\hline 95\% CI Lower Bound & 2.20 & 2.56 & 2.77 & 2.84 & 1.65 & 0.24 & 2.37 & & \\
\hline 95\% CI Upper Bound & 3.00 & 4.92 & 5.01 & 5.52 & 3.25 & 3.76 & 4.04 & & \\
\hline Minimum & 0 & 0 & 1 & 1 & 1 & 0 & 0 & & \\
\hline Maximum & 7 & 7 & 7 & 7 & 7 & 4 & 7 & & \\
\hline
\end{tabular}


214 and countries

\begin{tabular}{|c|c|c|c|c|c|c|c|c|c|c|}
\hline \multirow{2}{*}{$\begin{array}{l}\text { Item } \\
\text { Age }\end{array}$} & \multicolumn{7}{|c|}{ Category } & \multirow[t]{2}{*}{$\mathbf{X}^{2}$} & \multirow[t]{2}{*}{ Df } & \multirow[t]{2}{*}{$\mathbf{p}$} \\
\hline & 21-30 & \multicolumn{2}{|c|}{$31-40$} & $41-50$ & $51-60$ & \multicolumn{2}{|c|}{$>60$} & & & \\
\hline Item $1-n$ & 105 & \multicolumn{2}{|c|}{100} & 33 & 7 & \multicolumn{2}{|c|}{3} & & & \\
\hline $\begin{array}{l}\text { Item } 1 \\
\text { Mean rank }\end{array}$ & 115.14 & \multicolumn{2}{|c|}{129.00} & 137.33 & 149.43 & \multicolumn{2}{|c|}{102.83} & 4.254 & 4 & 0.340 \\
\hline Item2-n & 94 & \multicolumn{2}{|c|}{85} & 27 & 8 & \multicolumn{2}{|c|}{3} & & & \\
\hline $\begin{array}{l}\text { Item } 2 \\
\text { Mean rank }\end{array}$ & 104.90 & \multicolumn{2}{|c|}{112.58} & 101.06 & 145.31 & \multicolumn{2}{|c|}{110.67} & 3.898 & 4 & 0.420 \\
\hline Experience & $1-3$ & \multicolumn{2}{|c|}{$3-5$} & $5-10$ & $10-20$ & \multicolumn{2}{|c|}{$>\mathbf{2 0}$} & & & \\
\hline Item1-n & 77 & \multicolumn{2}{|c|}{29} & 60 & 53 & \multicolumn{2}{|c|}{29} & & & \\
\hline Item 1 & 112.93 & \multicolumn{2}{|c|}{134.48} & 122.05 & 127.93 & \multicolumn{2}{|c|}{144.03} & 5.095 & 4 & 0.278 \\
\hline \multicolumn{11}{|l|}{ Mean rank } \\
\hline Item2-n & 65 & \multicolumn{2}{|c|}{31} & 51 & 46 & \multicolumn{2}{|c|}{24} & & & \\
\hline Item 2 & 105.04 & \multicolumn{2}{|c|}{92.81} & 119.16 & 101.13 & \multicolumn{2}{|c|}{134.15} & 8.472 & 4 & 0.076 \\
\hline \multicolumn{11}{|l|}{ Mean rank } \\
\hline Sector & & \multicolumn{2}{|c|}{ Public } & Private & & \multicolumn{2}{|c|}{ Mixed } & & & \\
\hline Item1-n & & \multicolumn{2}{|l|}{94} & 145 & & \multicolumn{2}{|l|}{9} & & & \\
\hline \multicolumn{2}{|c|}{ Item 1 Mean rank } & 139.52 & & 116.18 & & 101.6 & & .252 & 2 & $0.027 *$ \\
\hline Item2-n & & 85 & & 125 & & 7 & & & & \\
\hline Item 2 Mean & rank & 99.72 & & 116.34 & & 90.7 & & 4.201 & 2 & 0.118 \\
\hline Country & Romania & Italy & France & Belgium & UK & $\mathbf{U E}$ & $\begin{array}{c}\text { Non- } \\
\text { UE }\end{array}$ & & & \\
\hline Item1-n & 111 & 36 & 22 & 20 & 21 & 7 & 31 & & & \\
\hline $\begin{array}{l}\text { Item } 1 \\
\text { Mean rank }\end{array}$ & 101.82 & 163.71 & 101.79 & 120.48 & 186.17 & 155.36 & 130.65 & 42.878 & 6 & 0.000 \\
\hline Item2-n & 102 & 27 & 19 & 19 & 20 & 6 & 24 & & & \\
\hline $\begin{array}{l}\text { Item } 2 \\
\text { Mean rank }\end{array}$ & 98.47 & 118.20 & 132.11 & 142.89 & 94.30 & 79.67 & 117.88 & $14.0 / 5$ & 0 & 0.021 \\
\hline
\end{tabular}


Table 5: Bonferroni correction for multiple comparisons of Kruskal Wallis test.

\begin{tabular}{llccccc} 
Group Versus (VS) & $\begin{array}{c}\text { Mean Ranks } \\
\text { VS }\end{array}$ & $\begin{array}{c}\text { Test } \\
\text { statistic }\end{array}$ & $\begin{array}{c}\text { Std. } \\
\text { error }\end{array}$ & $\begin{array}{c}\text { Std. test } \\
\text { statistic }\end{array}$ & p \\
\hline Item 1 & France-Italy & $101.09 / 163.71$ & 62.617 & 19.052 & 3.287 & 0.001 \\
& France UK & $101.09 / 186.17$ & -85.076 & 21.478 & -3.961 & 0.000 \\
& Romania-Italy & $101.82 / 163.71$ & -61.889 & 13.503 & -4.583 & 0.000 \\
& Romania-UK & $101.82 / 186.17$ & -84.347 & 16.753 & -5.035 & 0.000 \\
& Romania-Non-UE & $101.82 / 130.65$ & -28.826 & 14.301 & -2.016 & 0.044 \\
& Belgium-Italy & $120.48 / 163.71$ & 43.233 & 19.634 & 2.202 & 0.028 \\
& Belgium-UK & $120.48 / 186.18$ & -65.692 & 21.996 & -2.987 & 0.003 \\
& Non-UE-UK & $130.65 / 186.17$ & 55.522 & 19.897 & 2.790 & 0.005 \\
\hline Item 2 & UE-Belgium & $79.67 / 142.89$ & 63.228 & 28.976 & 2.182 & 0.029 \\
& UK-Belgium & $94.30 / 142.89$ & 48.595 & 19.823 & 2.451 & 0.014 \\
& Romania-France & $98 / 47 / 132.11$ & -33.640 & 15.461 & -2.176 & 0.030 \\
& Romania-Belgium & $98.47 / 142.89$ & -44.429 & 15.461 & -2.874 & 0.004
\end{tabular}

*Pairwise comparison results regarding Public versus Private Sector on Item1: Test statistic: 23.342, std error: 9.322 , Std. Test statistic: 2.504 and $p=0.037$

\section{Discussions}

\section{Informed Consent}

The results of the statistical analysis revealed that the physiotherapists from Italy and UK had been mostly focused on the complexity of the IC process so that 19 of 36 and 13 of 21 (Table 2) respectively provided adequate responses to the patient's consent with the treatment plan and the ethical aspects and legal IC.

The results are surprising given the differences and similarities between the analyzed groups. Thus, as in Belgium and UK, the physiotherapists have professional independence, with diagnostic attributions as autonomous practitioners, whereas in France, Italy, and Romania, physiotherapists have a secondary contact with a patient at the referral of a specialist physician and have no competence of diagnostic (33). Previous literature often advocates the need for a concise framework for IC in physiotherapy, given the specificity and dynamics of treatment in this medical division (34)(35). 
Although the need to obtain IC from the patient is found in national legislation, both in Romania and in other countries, there are probably several factors influencing the process of requesting and obtaining IC from patients. Five Romanian physiotherapists claimed the lack of IC and $36.03 \%$ associated this process by providing treatment information. In Romania, the heterogeneity of university studies, the lack of a professional association and a code of conduct for physiotherapists are elements that might influence this process. Also, in France, it is likely that the influence of this legal and ethical aspect is related to the type of university studies provided by the French higher education system. Starting in 2015, the reform of masso-kinesitherapy studies is taking place, extending for another two years, and reaching five years of university studies (36). At the European level, are voices that challenge the skills and abilities of physiotherapists in specific countries across the EU that say there is no uniformity in physiotherapy studies across the European Union. The Secretary-General of the Maso Therapy Order in France states that Belgium and France are the most demanding in terms of studies, and the weakest and most critical educational systems reported in the physiotherapist profession are those in Romania and Spain. (37). Our ethical aspects of this process are minimized.

245 The results obtained reveal that of the 248 respondents, $24.20 \%$ (Table 2) linked the IC process to simple patient information, s omitting the ethical and legal issues that were created and implemented as practice standards, continuing to use the IC process as a tool for detailing the treatment objectives and the techniques used (38)(24).

An important aspect to consider is professional autonomy and initial contact with the patient. Considering the legislative aspect, specific to each country, the physiotherapists performing the medical activity, only at the physician's indication, are having secondary contact with the patient, so the ethical and professional

252 responsibilities lie primarily with the physician and less with the physiotherapist. We cannot extrapolate 253 on this, because in Italy for example, where the situation is similar to Romania and physiotherapists work 254 under the guidance of a physician, 52.80\% (19) of the respondents responded appropriately to this item. 
Italian physiotherapists considering that the reason for requesting and obtaining IC is represented by the ethical, deontological, and legal nature of the profession and the process itself.

Differentiating response categories by the reason physiotherapists believe that IC is obtained has allowed us to point out important aspects of physiotherapists' perception of IC. So far, this aspect has not been studied from this perspective, and the responses suggest that the IC process is elaborate. In addition to legal and deontological considerations, obtaining IC is a useful tool that allows physiotherapists to establish a connection and a relationship with the patient. (32) (39)

It seems that the lack of a concrete framework for IC obtaining in physiotherapy, due to treatment specific and dynamics are negatively influencing the perceptions of physiotherapists regarding IC even after a century of professional development (6)(38).

\section{Assumed role in healthcare}

From the summary analysis of the results, it is observed that the highest percentage was attributed to the role in the physical rehabilitation process (21.67\%) (Table 3), omitting the other professional competences. It should be mentioned that the "Interdisciplinary" role was representative of the Romanian participants - 7 out of 10 responses. We want to emphasize this aspect because of the interdisciplinary relationship between Romanian physiotherapists and specialists, which presupposes a rather collaborative

271 relationship between the two and not a hierarchy, although as discussed previously, the physiotherapist

272 cannot apply physiotherapy techniques and methods without the referral of the physician. (40)

273 Most of the physiotherapists summarize their role in the healthcare process, at the level of restoring the 274 patient's functional capacity and the regaining of physical autonomy, although the role of physiotherapists

275 in healthcare is complex. The World Confederation of Physiotherapists (WCPT) states: "Physiotherapists 276 offer services that develop, maintain and restore the maximum ability for movement and functional 277 capacity of people. They can help people at any stage of life when movement and functionality are 278 threatened by aging, injury, illness, disorder, condition, or environmental factors. Physiotherapists help 
279 people maximize their quality of life, with regard to physical, psychological, emotional and social well-

280 being. They work in the health spheres of promotion, prevention, treatment/intervention, rehabilitation

281 and provision of services that ensure maximum independence in everyday life activities through

282 education, education and/or treatment (16). Physiotherapists from Italy and Belgium seemed to orient

283 themselves in a higher percentage with the complexity of the profession.

284 Most of the WCPT physiotherapists attributions are found in the categories of responses differentiated by

285 the present study (Table 3), but the proportion of physiotherapists that perceive their complex role in

286 healthcare is deficient. Although it is a profession that has been developing for more than 100 years in

287 Europe, the professional identity of physiotherapists is still in a complicated process, dynamic and with

288 various influences $(1)(3)(2)$.

289 The transition from student to practitioner, as well as the many elements that can influence the 290 professional development of physiotherapists profession. Graduation country, workplace, experience, 291 continuous professional training, ethical and legislative education, physiotherapist integration into the 292 medical team, lack of autonomy and the promotion of physiotherapy as an essential medical division in 293 patients 'health are elements that can influence physiotherapists' perception of their role in the healthcare 294 system (41) (42)

Comparative analysis

296 One of the issues investigated was the influence of factors such as age, work experience and country of 297 origin in the formation of professional identity and IC perceptions.

298 As far as the professional identity of physiotherapists is concerned, they are still in development and they 299 seem to have difficulties in terms of professional strength and integration into the medical team (43)(44).

300 The results of our research (Table 4) show that there are no differences in the perception of the role in the 301 health system or on the ethical aspects of IC based on age or work experience. In contrast, there was a 
difference in terms of IC issues and the public or private sector of activity. Physiotherapists performing public health work are thus more aware of the complexity of the IC process (Table 4).

In the comparative analysis on countries (Table 4), there is a statistically significant difference in the and Belgium, versus physiotherapists in the UK and Italy. The differences of physiotherapy programs available in many countries, mainly linked to the profile of the faculties: physical education or healthcare are elements that influence the formation of physiotherapists professional identity and professional ethics, including in the UK. (45).

Also, the importance of continuing professional education has proven to be an essential factor in the development of professional identity. Moreover, we want to emphasize that physiotherapists in Romania do not currently have an obligation to attend continuous professional training (46) (47). perception both on IC aspects, but also on the role in the healthcare system and the formation of professional identity, to the benefit of physiotherapists in the UK and Italy, to the detriment of physiotherapists in Romania, France, and Belgium. In Romania, physiotherapy program studies can be

317 either in a university with a medical profile or in a sports university. Also, in France and Belgium, this 318 specialization is also earned from a university study program with a physical education background.

319 Contact with the clinical component of the physiotherapist students is a factor affecting the professional training process, which takes shape during the physiotherapy studies $(48)(49)(50)(51)$.

\section{Conclusions}

322 The development of the professional identity of physiotherapists in Europe differs according to the 323 educational system and the present legislation. In countries where physiotherapy programs are belonging

324 to the medical sphere, physiotherapists have a greater sense of their professional role in healthcare, as 325 medical services providers. The heterogeneity of university studies, their duration, the presence of 
professional organizations, and legislation are factors that influence the perception and attitude of

327 physiotherapists on the IC process, both from a medical, ethical, and legal point of view.

328 The lack of a concrete framework for obtaining IC in physiotherapy is still felt in medical practice, and

329 the lack of professional activity of physiotherapists focused on prevention and prophylaxis is poorly

330 identified by them.

331 We recognize the limits of research through the small sample size and the inequality of the analyzed

332 groups, and we suggest continuing the research from this perspective to determine real factors which

333 require changes for the professional practice of physiotherapists at the European standards in all EU

334 countries.

\section{Refferences}

1. Hammond R, Cross, V, Moore, A, The construction of professional identity by physiotherapists: a qualitative study [Journal] // Physiotherapy. - 2016. - Vol. 102.

2. Holden M., Buck, E., Clark, M.,Szauter, K., Trumble, J. Professional identity formation in medical education: the convergence of multiple domains [Journal] // HEC Forum.. - 2012. - Vol.

3. Christmas S., Cribb, A. How does professional regulation affect the identity of health and care professionals: exploring the views of professionals. [Report] / UK Professional Standards Authority. - 2017

4. Ottoson A. The Manipulated History of Manipulations of Spines and Joints? Rethinking Orthopaedic Medicine Through the 19th Century Discourse of European Mechanical Medicine. Medicine Studies. 2011;: p. 83-116.

5. Ottosson A. Als Orthopäden noch Physiotherapeuten waren, oder warum es Physiotherapeuten an Geschichtsbewusstsein mangelt - Verhältnis von Orthopädie und Physiotherapie in Schweden im 19. Jahrhundert. Fachwissen: Geschichte der Physiotherapie. 2009. (German) 
6. Quin G. The Rise of Massage and Medical Gymnastics in London and Paris before the First World War. Canadian Bulletin of Medical History. 2017;: p. 206-229.

7. World Confederation of Physical Therapy [Internet]. Member Organisation.[cited 2019, Mar 7]. Available from: https://www.wcpt.org/members

8. The Association of Danish Physiotherapists. Danske Fysioterapeuter [Internet] .[cited 2019, Mar 7]. Available from: https://www.fysio.dk/in-english

9. Swedish Association of Physiotherapists. [Internet] .[cited 2019, Mar 7]. Available from: https://www.saco.se/en/english/our-23-unions/swedish-association-of-physiotherapists/.

10. Legea nr. 229/2016. privind organizarea și exercitarea profesiei de fizioterapeut, precum și pentru înființarea, organizarea și funcționarea Colegiului Fizioterapeuților din România; 2016 (Public law- Romanian) Eng Ethics. 2015;: p. 767-787.

13. European Commision. Internal Market-Free movement of professionals-Regulated professions database-Ranking . Geography of Mobility. Generic Name of profession- Physiotherapist. [Internet][cited 2019, Mar 7]. Available from: http://ec.europa.eu/growth/tools$\underline{\text { databases/regprof/index.cfm?action }=\text { profession\&id profession }=1250 \& \operatorname{tab}=\text { origin } 1}$

14. European Commission. Regulated Professions Database. Generic Name of professionPhysiotherapist [Internet], [cited 2019, Mar 6]. Available from: http://ec.europa.eu/growth/tools$\underline{\text { databases/regprof/index.cfm?action=profession } \& \text { id profession }=1250 \& \operatorname{tab}=\text { countries }}$

15. Mueller-Winkler B. Supporting overseas-qualified physiotherapists during the transition period into UK practice. World Confederation of Physical Therapy Congress 2015. Physiotherapy; 2015. Vol 101. Supplement 1

16. World Confederation of Physical Therapy. What is physical therapy. [Internet]c 2016 [cited 2019, Mar 7]. Available from: . https://www.wcpt.org/what-is-physical-therapy 
17. Suciu O, Onofrei RR, Totorean AD, Suciu SC, Amaricai EC. Gait analysis and functional outcomes after twelve-week rehabilitation in patients with surgically treated ankle fractures. Gait Posture. 2016;49:184-189.

18. NCD Alliance [Internet]; c 2016 [cited 2019, Jan 23]. Available from: https://ncdalliance.org/printpdf/news-events/blog/the-4th-leading-cause-of-death-worldwidephysical-inactivity-is-an-urgent-public-health-priority.

19. Mosadeghrad AM. Factors influencing healthcare service quality. Int J Health Policy Manag. 2014 Jul; 3(2): 77-89.

20. WHO. Global Health and Aging [Internet] NIH Publication; 2011. [cited 2019, Jan 25] Available from: https://www.who.int/ageing/publications/global_health.pdf

21. Moffett JAK, Richardson PH. The influence of the physiotherapist-patient relationship on pain and disability. Physiotherapy Theory and Practice. 1997. Vol 13, Issue 1, 89-96. https://doi.org/10.3109/09593989709036451

22. Hall AM, Ferreira PH, Maher CG, Latimer J, Ferreira ML. The influence of the therapist-patient relationship on treatment outcome in physical rehabilitation: a systematic review. Phys Ther. 2010 Aug;90(8):1099-110. doi: 10.2522/ptj.20090245

23. Jorgensen P. Concepts of body and health in physiotherapy: The meaning of the social/cultural aspects of life. Physiotherapy Theory and Practice. 2000; p. 105-115.

24. Poulis I. Bioethics and physiotherapy. J Med Ethics. 2007 Aug; 33(8): 435-436. doi: 10.1136/jme.2007.021139 Med Ethics. 2007; p. 435-436.

25. Delany C, Edwards I, Fryer C. How physiotherapists perceive, interpret, and respond to the ethical dimensions of practice: A qualitative study. Physiotherapy Theory and Practice. 2018; 28: p. $1-14$.

26. Guccione A. Ethical Issues in Physical Therapy Practice. Physical Therapy Journal. 1980; 60: p. $1264-1272$. 
27. Haas J. Ethical Considerations of Goal-setting for patient care in rehabilitation. American Journal of Physical Medicine \& Rehabilitation. 1993; 72(4): p. 228-232.

28. Praestegaard J, Gard G. The perceptions of Danish physiotherapists on the ethical issues related to the physiotherapist-patient relationship during the first session: a phenomenological approach. BMC Medical Ethics. 2011; 12(21).

29. Praestegaard J, Gard G, Glasdam S. Practicing physiotherapy in Danish private practice: an ethical perspective. Medicine, Health Care and Philosophy. 2013; 16(3).

30. Potter M, Gordon S, Hamer P. The Physiotherapy experience in private practice: The patient's perspective. Australian Journal of Physiotherapy. 2003; 49(3): p. 195-202.

31. Edwards I, Delany CM, Towsend AF, Swisher LL. New Perspectives on the Theory of Justice: Implications for Physical Therapy Ethics and Clinical Practice. Physical Therapy. 2011 November; 91(11).

32. Fennety A, Harman K, Hoens A, Basset R. Informed consent practices of physiotherapists in the treatment of low back pain. Manual therapy $\cdot 2009 \mathrm{Feb} ; 007$.

33. World Confederation of Physical Therapy [Internet]; c 2018. Italy Profile Report; [ cited 2019, Feb 14]. Available from https://www.wcpt.org/sites/wcpt.org/files/files/cds/reports/2018/150084.pdf

34. Hudon A, Drolet M-J, Jones BW. Ethical Issues Raised by Private Practice Physiotherapy Are More Diverse than First Meets the Eye: Recommendations from a Literature Review. Physiotherapy Canada. 2015; 67(2).

35. Galeoto G, Mollica R, Astorino O, Cecchi R. Informed consent in physiotherapy: proposal of a form. Giornale Italiano di Medicina del Lavoro ed Ergonomia. 2015; 37(4): p. 245-254.

36. Studyrama [Internet] Etudes de kiné : les nouveautés suite à la réforme.[cited 2019, Mar 12] Available from: https://www.studyrama.com/revision-examen/concours-sante-paramedicalsocial/etudes-de-kine-les-nouveautes-suite-a-la-reforme/ (French) 
37. Le Monde. M Campus. Le parcours abberant des etudiants kines [Internet]. Nunes E . 2016, oct. [cited 2019, Mar 7]. Available from: https://www.lemonde.fr/campus/article/2016/10/28/leparcours-aberrant-des-etudiants-kines 5021999 4401467.html (French)

38. Delany C. In private practice, informed consent is interpreted as providing explanations rather than offering choices: a qualitative study. Australian Journal of Physiotherapy 53:171-177. 2007; 53.

39. Copnell G. Informed consent in physiotherapy practice: it is not what is said but how it is said. Physiotherapy. 2018; 104(1): p. 67-71.

40. Ministerul Sănătăţii. Legea nr. 200/2004 privind recunoaşterea diplomelor şi calificărilor profesionale pentru profesiile reglementate din România. (Public law- Romanian) from physiotherapy student to interprofessional team member. Physiotherapy. 2011; 97: p. 139144.

42. Hammond R. The construction of physiotherapists' identities through collective memory work. (doctoral thesis). University of Brighton. 2013. professional identity: an exploratory survey. Physiotherapie Canada. 1992; 44(4): p. 31-35. Physiotherapy Theory and Practice. 1988; 14(1): p. 23-32.

45. Macom D, Scott A. Professional relations in sport healthcare: Workplace responses to organisational change. Social Science \& Medicine. 2011; 72(4): p. 513-520.

46. Gunn H, Goding L. Continuing Professional Development of physiotherapists based in community primary care trusts: a qualitative study investigating perceptions, experiences and outcomes. Physiotherapy. 2009; 95(3): p. 209-214.

47. Richardson B. Professional socialisation and professionalisation. Physiotherapy. 1999; 85(9): p. 461-467. 
48. Dumitru IH. Physiotherapy in Romania-International perspectives. [Internet]; c 2015; [cited 2019,

Mar 5]. Available from: http://www.fysiot.ee/wp-content/uploads/2015/08/PT-inROMANIA_2.pdf. (Romanian)

49. Broberg C, Aars M, Beckmann K, Emaus N, Lehto P, Lähteenmäki M-I et al. A Conceptual Framework for Curriculum Design in Physiotherapy Education - an International Perspective. Advances in Physiotherapy. 2003; 5(4): p. 161-168.

50. Staes FFGM, Stappaerts KH, Myles S. Physiotherapy Programmes in Europe: A Preliminary Report. Advances in Physiotherapy. 2001; 3(1): p. 39--43. qualitative study. Medical Education Online. 2015; 20(1). 